\title{
Sequential ATRA/Reductive Cyclopropanation Reactions with a Ruthenium Catalyst in the Presence of Manganese
}

\author{
Mariano A. Fernández-Zúmel, ${ }^{[a]}$ Charlotte Buron, ${ }^{[a]}$ and Kay Severin*[a]
}

Keywords: Cyclopropanation / Radical reactions / Reduction / Ruthenium / Manganese

Atom-transfer radical addition (ATRA) reactions of ethyl trichloroacetate, dichloromalononitrile, or diethyl 2,2-dichloromalonate with olefins followed by dechlorination have provided functionalized cyclopropanes in one step. The $\mathrm{Ru}^{\mathrm{III}}$ complex $\left[\mathrm{Cp}^{*} \mathrm{RuCl}_{2}\left(\mathrm{PPh}_{3}\right)\right]$ was used as a catalyst precursor and commercial Mn powder as reducing agent. Reactions with the less activated substrate ethyl dichloroacetate gave ATRA products with high turnover numbers but cyclopropanation was not observed.

\section{Introduction}

Transition-metal-catalyzed atom-transfer radical addition (ATRA) reactions allow the coupling of halogenated compounds to olefins. ${ }^{[1,2]}$ In recent years, catalysts and reaction conditions have been optimized and nowadays it is possible to perform highly efficient and selective ATRA reactions with a wide range of substrates. ${ }^{[1]}$ Many transition metals are able to catalyze ATRA reactions, but most studies have focused on copper ${ }^{[3]}$ and ruthenium ${ }^{[4]}$ complexes. These complexes are particularly effective catalysts if they are used in conjunction with reducing agents. ${ }^{[1 \mathrm{a}, 5]}$ Different reagents have been used in this context, including magnesium powder, ${ }^{[6]}$ the diazo compounds $\mathrm{AIBN}^{[7]}$ and $\mathrm{V}-70,{ }^{[8]}$ and ascorbic acid. ${ }^{[9]}$ The role of these reagents is to convert inactive $\mathrm{Cu}^{\mathrm{II}}$ and $\mathrm{Ru}^{\mathrm{III}}$ complexes into active $\mathrm{Cu}^{\mathrm{I}}$ and $\mathrm{Ru}^{\mathrm{II}}$ complexes.

We recently reported that the products of ATRA reactions between olefins and activated dichloro compounds can be converted into cyclopropanes by dechlorination with $\mathrm{Mg}$ (Scheme 1). ${ }^{[10]}$ The cyclopropanations can be performed as one-pot-two-step reactions. First, a 1,3-dichloride is formed in an ATRA process with $\left[\mathrm{Cp} * \mathrm{RuCl}_{2}\left(\mathrm{PPh}_{3}\right)\right]$ as the catalyst precursor and $\mathrm{Mg}$ as reducing agent. The ATRA reaction is performed in a nonpolar organic solvent such as toluene. Subsequent addition of the more polar THF induces dechlorination to give the final cyclopropane.

An advantage of this cyclopropanation reaction is the fact that functionalized cyclopropanes can be obtained without the use of potentially problematic diazo compounds. However, there are also limitations. The reaction has to be performed in a two-step fashion because THF,

[a] Institut des Sciences et Ingénierie Chimiques, École

Polytechnique Fédérale de Lausanne (EPFL),

1015 Lausanne, Switzerland

Fax: +41-21-693-9305

E-mail: kay.severin@epfl.ch

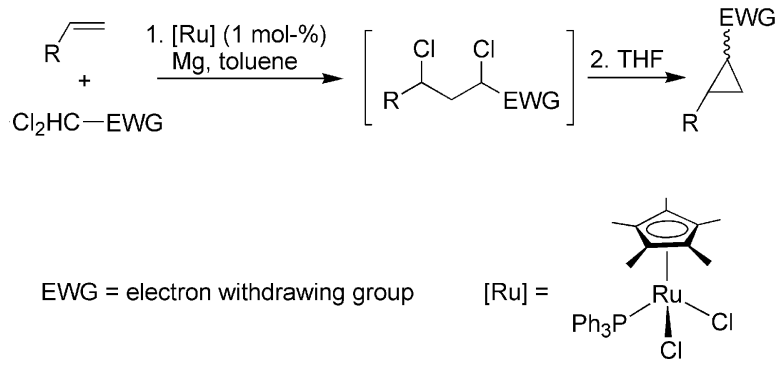

Scheme 1. Synthesis of cyclopropanes by sequential ATRA/dechlorination reactions. ${ }^{[10]}$

which is required for the dechlorination step, is not compatible with the ATRA reaction ( $\mathrm{Mg}$ reacts with the chlorinated starting material if THF is added at the beginning of the reaction). Furthermore, we encountered difficulties with highly activated dichlorides such as $\mathrm{Cl}_{2} \mathrm{C}(\mathrm{CN})_{2}$ or $\mathrm{Cl}_{3} \mathrm{CCO}_{2}$ Et. These substrates undergo ATRA reactions but fail to give cyclopropanes in acceptable yields. As a consequence, it was not possible to synthesize cyclopropanes with two electron-withdrawing groups in geminal positions. Below we report that these limitations can be overcome if $\mathrm{Mn}$ is used as a reducing agent instead of $\mathrm{Mg}$. The new Mnbased procedure allows one-step olefin cyclopropanation reactions to be performed with highly activated dichlorides to give difunctional cyclopropanes in good yields.

\section{Results and Discussion}

To address the shortcomings of our reported cyclopropanation procedure with $\mathrm{Mg}$, we had to find an alternative reducing agent with the following characteristics: 1) It should be able to reduce the $\mathrm{Ru}^{\mathrm{III}}$ catalyst precursor, 2) it should be largely inert towards the 1,1-dichloride starting material, and 3 ) it should be able to promote the reductive intramolecular coupling of the intermediate 1,3-dichloride. 
Metallic manganese appeared to be an attractive choice. $\mathrm{Mn}$ is cheap, nontoxic, and it has a $\mathrm{M}^{\mathrm{II}} / \mathrm{M}$ reduction potential that is intermediate between that of $\mathrm{Zn}$ and $\mathrm{Mg} .{ }^{[11]} \mathrm{The}$ functional group tolerance of organomanganese compounds is very good ${ }^{[12]}$ and commercial Mn powder is not very reactive towards organyl halides. ${ }^{[13,14]} \mathrm{Mn}^{0}$ has been employed as a selective stoichiometric reductant for reactions with chromium, ${ }^{[15]}$ titanocene, ${ }^{[16]}$ and nickel complexes. ${ }^{[17]}$ Its use as a reducing agent in Ru-catalyzed ATRA reactions is, to the best of our knowledge, unprecedented.

To test the suitability of Mn we first investigated the coupling of ethyl dichloroacetate with styrene (Scheme 2). The reaction was performed at room temperature with $\left[\mathrm{Cp}^{*} \mathrm{RuCl}_{2}\left(\mathrm{PPh}_{3}\right)\right]$ as catalyst precursor $(0.1 \mathrm{~mol}-\%)$ using $\mathrm{THF}$ as the solvent. An excess of commercial Mn powder (5 equiv. with respect to styrene) was added to the reaction mixture. After only $1 \mathrm{~h}$, we observed the clean formation of the ATRA product ethyl 2,4-dichloro-4-phenylbutanoate ( $86 \%$ yield). However, we did not observe the formation of the corresponding cyclopropane, even if the reaction mixture was heated at $60^{\circ} \mathrm{C}$.

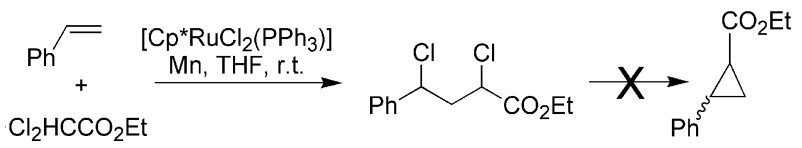

Scheme 2. ATRA reaction between ethyl dichloroacetate and styrene.

The combination of $\left[\mathrm{Cp}^{*} \mathrm{RuCl}_{2}\left(\mathrm{PPh}_{3}\right)\right]$ and $\mathrm{Mn}$ was found to be a very potent catalyst system for ATRA reactions of ethyl dichloroacetate. Lowering the $\mathrm{Ru}$ concentration to $0.02 \mathrm{~mol}-\%$ still gave the coupling product in $78 \%$ yield (Table 1, entry 1). The high turnover numbers indicate that $\mathrm{Mn}$ is able to fulfill the dual role of reducing agent in ATRA reactions: 1) Activation of the catalyst precursor and 2) constant regeneration of the $\mathrm{Ru}^{\mathrm{II}}$ catalyst from $\mathrm{Ru} \mathrm{u}^{\mathrm{III}}$ complexes, which are formed as a result of termination reactions. ${ }^{[5]} \mathrm{Mn}$ alone or a mixture of $\mathrm{Mn}$ and $\mathrm{MnCl}_{2}$ did not promote the ATRA reaction, which corroborates the crucial role of the $\mathrm{Ru}$ catalyst.

Table 1. ATRA reactions between ethyl dichloroacetate and olefins catalyzed by $\left[\mathrm{Cp}^{*} \mathrm{RuCl}_{2}\left(\mathrm{PPh}_{3}\right)\right]$ in the presence of $\mathrm{Mn}$. ${ }^{[\mathrm{a}]}$

\begin{tabular}{lllcc}
\hline & Olefin & Ru/Olefin & $t[\mathrm{~h}]$ & Yield [\%] \\
\hline 1 & styrene & $1: 5000$ & 24 & 78 \\
2 & $p$-chlorostyrene & $1: 5000$ & 48 & 93 \\
3 & $\alpha$-methylstyrene & $1: 1000$ & 24 & 83 \\
4 & 1-hexene & $1: 250$ & 24 & 83
\end{tabular}

[a] Reaction conditions: $\left[\mathrm{Cl}_{2} \mathrm{HCCO}_{2} \mathrm{Et}\right]=2.74 \mathrm{M}$, [olefin $]=1.37 \mathrm{M}$, $[\mathrm{Mn}]=5$ equiv. with respect to the olefin, THF, room temp. The yield was determined by ${ }^{1} \mathrm{H}$ NMR spectroscopy. The conversion of the olefin was quantitative in all cases.

We also examined the ATRA reaction of ethyl dichloroacetate with other olefins. By using between 0.4 and $0.02 \mathrm{~mol}-\% \mathrm{Ru}$, we were able to obtain the corresponding 1,3-dichlorides in good yields (Table 1). The performance of the $\mathrm{Ru} / \mathrm{Mn}$ catalyst system in these reactions was very good and comparable to those of $\mathrm{Ru}$ catalysts used in combination with $\mathrm{Mg}$.

Next we examined ATRA reactions with the more activated ethyl trichloroacetate using conditions similar to those described above. As was observed for the dichlorinated substrate, the ATRA product was formed rapidly. However, the reaction did not stop at that stage but proceeded to give the desired cyclopropane 1 (Scheme 3).

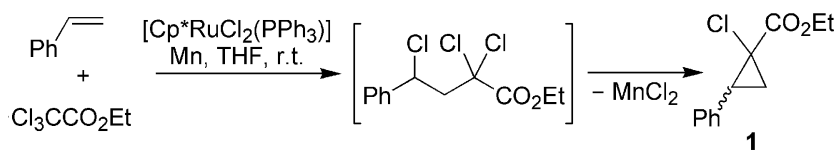

Scheme 3. ATRA/dechlorination reaction between ethyl trichloroacetate and styrene.

Optimization of the reaction conditions revealed that a slightly elevated temperature of $60^{\circ} \mathrm{C}$ is advantageous. Lowering the styrene concentration to $0.1 \mathrm{M}$ and using 4 equiv. of ethyl trichloroacetate also improved the yield of the cyclopropane. The low styrene concentration helps to avoid the addition of a second olefin to the intermediate 1,3-dichloride, a process that we have recently investigated in more detail. ${ }^{[18]}$ The excess of the chlorinated substrate is beneficial because $\mathrm{Mn}$ reacts to some extent with the highly activated trichloro ester (GC analysis revealed the formation of sizeable amounts of a diester resulting from homocoupling of ethyl trichloroacetate).

By using the optimized conditions, we performed ATRA/ dechlorination reactions with ethyl trichloroacetate and different aromatic olefins, which gave the corresponding cyclopropanes $\mathbf{1}-\mathbf{3}$ as a mixture of isomers in yields of around $70 \%$ (Table 2, entries 1-3). The isolated yields were lower due to loss of product during chromatographic purification.

Ethyl 1-chloro-2-phenylcyclopropane-1-carboxylate (1) has previously been made by $\mathrm{Rh}$-catalyzed reaction of styrene with ethyl $\alpha$-chlorodiazoacetate, a reagent that decomposes rapidly at room temperature. ${ }^{[19]}$ On the other hand, 1 has also been prepared in three steps from 1,1-dichloro-2phenylcyclopropane. ${ }^{[20]}$ Our one-pot procedure based on commercially available starting materials therefore represents an interesting synthetic alternative, even though the isolated yield is not very high.

When ethyl trichloroacetate was replaced by dichloromalononitrile, the cyclopropane-1,1-dicarbonitriles 4-8 were obtained in isolated yields of $51-83 \%$ (Table 2 , entries 4-8). An increased catalyst loading of $5 \mathrm{~mol}-\%$ was employed in these reactions. Alternative ways of preparing cyclopropane-1,1-dicarbonitriles involve the reductive cyclization of an appropriate allylic bromide, ${ }^{[21]}$ the photoinitiated addition of bromomalonitrile to an olefin followed by cyclizative dehydrobromination, ${ }^{[22]}$ the $\mathrm{PhI}(\mathrm{OAc})_{2}$-mediated oxidative addition of malononitrile to olefins, ${ }^{[23]}$ and the indium-mediated reductive coupling of dibromomalonitrile with olefins. ${ }^{[24]}$ The last two methods are one-step procedures but the cyclopropanes are obtained in poor yields. 
Table 2. ATRA/dechlorination reactions catalyzed by $\left[\mathrm{Cp}^{*} \mathrm{RuCl}_{2}\left(\mathrm{PPh}_{3}\right)\right]$ in the presence of $\mathrm{Mn}$. ${ }^{\text {[a] }}$

[d]

[a] Reaction conditions: $\left[\mathrm{Cl}_{2} \mathrm{CRR}^{\prime}\right]=0.40 \mathrm{M}$, [olefin] $=0.10 \mathrm{M},[\mathrm{Ru}]=1.0 \mathrm{~mm}(1.0 \mathrm{~mol}-\%),[\mathrm{Mn}]=5$ equiv. with respect to the olefin, THF, $60{ }^{\circ} \mathrm{C}$. [b] Crude yields determined by GC. The isolated yields are given in parentheses. [c] Use of 2 mol- $\%$ catalyst. [d] Use of 5 mol- $\%$ catalyst. [e] $\left[\mathrm{Cl}_{2} \mathrm{C}\left(\mathrm{CO}_{2} \mathrm{Et}\right)_{2}\right]=0.25 \mathrm{M}$.

We have also investigated the reaction of styrene with diethyl 2,2-dichloromalonate. The corresponding cyclopropane 9 was obtained in $66 \%$ yield (Table 2, entry 9). Geminal cyclopropanedicarboxylates such as $\mathbf{9}$ are valuable precursors for a variety of reactions. ${ }^{[25]}$ They are most often prepared by the reaction of an alkylidenemalonate with dimethylsulfoxonium or dimethylsulfonium methylides. ${ }^{[25 a, 26]}$ Other methodologies involve the metal-catalyzed reactions of an olefin with diazomalonates ${ }^{[27]}$ or iodonium ylides. ${ }^{[28]}$

To establish the role of the Ru complex in the dechlorination process, we studied the cyclization of the isolated ATRA adduct ethyl 2,2,4-trichloro-4-phenylbutanoate. The reaction with 10 equiv. of $\mathrm{Mn}$ in THF did not give detectable amounts of cyclopropane 1, even not after $24 \mathrm{~h}$. However, when the reducing agent was preactivated by stirring it for 2 min with $\mathrm{ClSiMe}_{3}$ (0.1 equiv.) and $\mathrm{PbCl}_{2}$ ( 0.0025 equiv., both relative to $\mathrm{Mn}),{ }^{[13]}$ the corresponding cyclization product was obtained in $81 \%$ yield (determined by GC) after $3 \mathrm{~h}$ (Scheme 4). These results show that the cyclization step can be performed without the Ru catalyst. It is thus unlikely that the Ru complex is involved in the dechlorination. However, it may contribute to the activation of Mn, which occurs during the ATRA step.

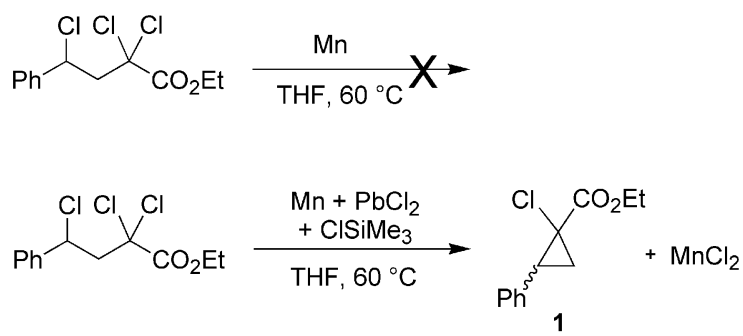

Scheme 4. The dechlorination reaction of ethyl 2,2,4-trichloro-4phenylbutanoate requires activated $\mathrm{Mn}$ powder. 


\section{Conclusions}

Transition-metal-catalyzed ATRA reactions are best performed in the presence of reducing agents. ${ }^{[5]}$ We have shown that commercial Mn powder is a potent reagent in this context. The Ru-catalyzed coupling of ethyl dichloroacetate to styrene, for example, can be achieved with only $0.02 \mathrm{~mol}-\%$ of $\mathrm{Ru}$. An important advantage of $\mathrm{Mn}$ is the possibility of performing sequential ATRA/dechlorination reactions ${ }^{[29]}$ with highly activated dichloro compounds such as ethyl trichloroacetate, dichloromalononitrile, or diethyl 2,2-dichloromalonate. These reactions provide synthetically interesting cyclopropanes in one step from easily available starting materials.

\section{Experimental Section}

General: All reactions were performed under dry nitrogen using a glovebox. The solvents and liquid substrates were distilled from appropriate drying agents and stored under nitrogen. The olefinic substrates were stored at a temperature of $-18{ }^{\circ} \mathrm{C}$. The solvents and chlorinated esters as well as the solids were kept at room temperature. The catalyst precursor $\left[\mathrm{Cp} * \mathrm{RuCl}_{2}\left(\mathrm{PPh}_{3}\right)\right]^{[30]}$ and the substrate $\mathrm{Cl}_{2} \mathrm{C}\left(\mathrm{CO}_{2} \mathrm{Et}\right)_{2}{ }^{[31]}$ were synthesized according to literature procedures. Mn powder (140-325 mesh, 99.6\%) was purchased from AlfaAesar. The ${ }^{1} \mathrm{H}$ and ${ }^{13} \mathrm{C}$ NMR spectra were recorded with a Bruker Avance DPX 400 spectrometer with the residual solvents as internal standards. All spectra were recorded at room temperature. Column chromatography was performed using silica gel 60 (230400 mesh, $0.04-0.063 \mathrm{~nm}$ ) from Fluka. Plates coated with silica gel 60 F245 from Merck were used for thin-layer chromatography. Elemental analyses were performed with a EA $1110 \mathrm{CHN}$ instrument.

General Procedure for the ATRA Reactions: The desired amount of a stock solution of complex 1 in THF was added to a $2.0 \mathrm{~mL}$ vial that contained Mn powder $(370 \mathrm{mg})$. A stock solution of the chlorinated compound, the olefin, and mesitylene as an internal standard was added to the vial and the total volume was increased to $1000 \mu \mathrm{L}$ with $\operatorname{THF}([$ olefin $]=1.38 \mathrm{M}$, [chlorinated compound $]=$ $2.76 \mathrm{M}$, [internal standard] $=138 \mathrm{~mm}$ ). The resulting solution was stirred at room temperature. After the given time, a sample $(20 \mu \mathrm{L})$ was removed from the reaction mixture, diluted with $\mathrm{CDCl}_{3}$ $(500 \mu \mathrm{L})$, and analyzed by ${ }^{1} \mathrm{H}$ NMR spectroscopy.

General Procedure for the Sequential ATRA/Reductive Cyclopropanation Reactions: Mn powder (10 equiv.) and THF were added to a flask containing the desired amount of the Ru catalyst. The olefin ( $2.0 \mathrm{mmol})$ and the chlorinated substrate $(8.0 \mathrm{mmol}, 4$ equiv.) were added $\left([\text { olefin }]_{\text {final }}=0.10 \mathrm{M}\right)$ and the mixture was stirred at $60^{\circ} \mathrm{C}$. After the given time, the crude reaction mixture was diluted with hexane, filtered through kieselgur, and the solvent was removed under reduced pressure. The product was purified by flash chromatography.

Ethyl 1-Chloro-2-phenylcyclopropane-1-carboxylate (1): Flash chromatography on silica gel, hexane/ethyl acetate $=7: 1$. The product was obtained as a mixture of two diastereoisomers (ratio from ${ }^{1} \mathrm{H}$ NMR: cis/trans $=6: 1$ ). The spectroscopic data for the product correspond to those previously described in the literature. ${ }^{[32]}$

Ethyl 1-Chloro-2-(4-fluorophenyl)cyclopropane-1-carboxylate (2): Flash chromatography on silica gel, hexane/ethyl acetate $=6: 1$. The product was obtained as a mixture of two diastereoisomers (ratio from ${ }^{1} \mathrm{H}$ NMR: cisltrans $=7: 1$ ). The diastereoisomers were as- signed in analogy to the literature report. ${ }^{[20]}$ The NMR spectroscopic data of the main product (cis isomer) is as follows: ${ }^{1} \mathrm{H}$ NMR $\left(\mathrm{CDCl}_{3}, 400 \mathrm{MHz}\right): \delta=1.36\left(\mathrm{t}, J=7.2 \mathrm{~Hz}, 3 \mathrm{H}, \mathrm{CH}_{3}\right), 1.70-1.73$ (m, $\left.1 \mathrm{H}, \mathrm{CH}_{2}\right), 2.15-2.19\left(\mathrm{~m}, 1 \mathrm{H}, \mathrm{CH}_{2}\right), 3.06(\mathrm{dd}, J=8.9,9.9 \mathrm{~Hz}$, $1 \mathrm{H}, \mathrm{ArCH}), 4.28\left(\mathrm{~m}, 2 \mathrm{H}, \mathrm{OCH}_{2}\right), 7.03-7.22(\mathrm{~m}, 4 \mathrm{H}$, aromatic) ppm. ${ }^{13} \mathrm{C} \mathrm{NMR}\left(\mathrm{CDCl}_{3}, 100 \mathrm{MHz}\right): \delta=14.1\left(\mathrm{CH}_{3}\right), 23.7$ $\left(\mathrm{CH}_{2}\right), 32.9(\mathrm{ArCH}), 44.7(\mathrm{CCl}), 62.7\left(\mathrm{OCH}_{2}\right), 115.0-131.1$ (m, aromatic), $163.2(\mathrm{~d}, J=44.8 \mathrm{~Hz}, \mathrm{CF}), 170.1$ (COOEt) ppm.

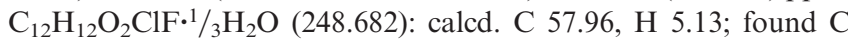
57.94, H 5.02.

Ethyl 1-Chloro-2-(4-methoxyphenyl)cyclopropane-1-carboxylate (3): Flash chromatography on silica gel, hexane/ethyl acetate $=6: 1$. The product was obtained as a mixture of two diastereoisomers (ratio from ${ }^{1} \mathrm{H}$ NMR: cis/trans $=2: 1$ ). The assignment of the diastereoisomers was performed in analogy to the literature report. ${ }^{[20] ~}{ }^{1} \mathrm{H}$ NMR $\left(\mathrm{CDCl}_{3}, 400 \mathrm{MHz}\right): \delta=0.96\left(\mathrm{t}, J=7.2 \mathrm{~Hz}, 3 \mathrm{H}, \mathrm{CH}_{3}\right.$, trans $), 1.36$ (t, $J=7.0 \mathrm{~Hz}, 3 \mathrm{H}, \mathrm{CH}_{3}$, cis), $1.70-1.78\left(\mathrm{~m}, 2 \mathrm{H}, \mathrm{CH}_{2}\right.$, cis + trans), 2.15-2.19 (m, $2 \mathrm{H}, \mathrm{CH}_{2}$, cis + trans), 2.96-3.06 (m, $2 \mathrm{H}, \mathrm{ArCH}$, cis + trans $), 3.85-3.97\left(\mathrm{~m}, 2 \mathrm{H}, \mathrm{OCH}_{2}\right.$, trans $), 4.26-4.32(\mathrm{~m}, 2 \mathrm{H}$, $\mathrm{OCH}_{2}$, cis $), 6.82-7.20(\mathrm{~m}, 8 \mathrm{H}$, aromatic, $2 \mathrm{H}$, cis + trans $) \mathrm{ppm}$. ${ }^{13} \mathrm{C} \mathrm{NMR}\left(\mathrm{CDCl}_{3}, 100 \mathrm{MHz}\right): \delta=13.8\left(\mathrm{CH}_{3}\right), 14.2\left(\mathrm{CH}_{3}\right), 21.9$ $\left(\mathrm{CH}_{2}\right), 23.6\left(\mathrm{CH}_{2}\right), 32.2(\mathrm{ArCH}), 36.3(\mathrm{ArCH}), 44.2(\mathrm{CCl}), 45.0$ $(\mathrm{CCl}), 55.2\left(\mathrm{OCH}_{3}\right), 61.9\left(\mathrm{OCH}_{2}\right), 62.6\left(\mathrm{OCH}_{2}\right), 113.5,113.6$, $126.4,126.5,130.0,130.5$ (aromatic), $158.9\left(\mathrm{COCH}_{3}\right), 159.0$ $\left(\mathrm{COCH}_{3}\right), 167.4$ (COOEt), 170.3 (COOEt) ppm. Due to the overlap of peaks in the ${ }^{13} \mathrm{C} \mathrm{NMR}$ spectrum, the correct number of peaks could not be observed. $\mathrm{C}_{13} \mathrm{H}_{15} \mathrm{O}_{3} \mathrm{Cl}^{1}{ }_{1}{ }_{3} \mathrm{H}_{2} \mathrm{O}$ (260.718): $\mathrm{C} 59.89, \mathrm{H}$ 6.06; C 59.73, H 6.05 .

Cyclopropanes 4-9: Flash chromatography on silica gel, hexane/ ethyl acetate $=4: 1(4-8)$ or 7:1 (9). The spectroscopic data for the products correspond to those previously described in the literature. ${ }^{[22,33-36]}$

\section{Acknowledgments}

This work was supported by the Swiss National Science Foundation and by the École Polytechnique Fédérale de Lausanne (EPFL).

[1] a) W. T. Eckenhoff, T. Pintauer, Catal. Rev. 2010, 52, 1-59; b) T. Pintauer, K. Matyjaszewski, Chem. Soc. Rev. 2008, 37, 10871097; c) K. Severin, Curr. Org. Chem. 2006, 10, 217-224; d) L. Delaude, A. Demonceau, A. F. Noels, Top. Organomet. Chem. 2004, 11, 155-171; e) H. Nagashima in Ruthenium in Organic Synthesis (Ed.: S.-I. Murahashi), Wiely-VCH, Weinheim, 2004, pp. 333-343; f) A. J. Clark, Chem. Soc. Rev. 2002, 31, 1-11; g) K. I. Kobrakov, A. V. Ivanov, Chem. Heterocycl. Compd. 2001, 37, 529-539; h) R. A. Gossage, L. A. van de Kuil, G. van Koten, Acc. Chem. Res. 1998, 31, 423-431; i) J. Iqbal, B. Bhatia, N. K. Nayyar, Chem. Rev. 1994, 94, 519-564; j) F. Minisci, Acc. Chem. Res. 1975, 8, 165-171.

[2] For pioneering studies, see: a) M. S. Kharasch, E. V. Jensen, W. H. Urry, Science 1945, 102, 128-128; b) M. S. Kharasch, W. H. Urry, E. V. Jensen, J. Am. Chem. Soc. 1945, 67, 16261626.

[3] For selected examples, see: a) J. Muñoz-Molina, T. R. Belderraín, P. J. Pérez, Inorg. Chem. 2010, 49, 642-645; b) F. Ghelfi, F. Roncaglia, M. Pattarozzi, V. Giangiordano, G. Petrillo, F. Sancassan, A. F. Parsons, Tetrahedron 2009, 65, 10323-10333; c) M. Pattarozzi, F. Roncaglia, V. Giangiordano, P. Davoli, F. Prati, F. Ghelfi, Synthesis 2010, 694-700; d) A. J. Clark, P. Wilson, Tetrahedron Lett. 2008, 49, 4848-4850; e) J. A. Bull, M. G. 
Hutchings, C. Luján, P. Quayle, Tetrahedron Lett. 2008, 49, 1352-1356; f) R. N. Ram, N. Kumar, Tetrahedron Lett. 2008, 49, 799-802; g) J. A. Bull, M. G. Hutchings, P. Quayle, Angew. Chem. 2007, 119, 1901; Angew. Chem. Int. Ed. 2007, 46, 18691872; h) A. J. Clark, J. V. Geden, S. Thom, P. Wilson, J. Org. Chem. 2007, 72, 5923-5926; i) J. M. Muñoz-Molina, A. Caballero, M. M. Díaz-Requejo, S. Trofimenko, T. R. Belderraín, P. J. Pérez, Inorg. Chem. 2007, 46, 7725-7730; j) C. V. Stevens, E. Van Meenen, K. G. R. Masschelein, Y. Eeckhout, W. Hooghe, B. D'hondt, V. N. Nemykin, V. V. Zhdankin, Tetrahedron Lett. 2007, 48, 7108-7111.

[4] For selected examples, see: a) R. P. Nair, T. H. Kim, B. J. Frost, Organometallics 2009, 28, 4681-4688; b) R. J. Lundgren, M. A. Rankin, R. McDonald, M. Stradiotto, Organometallics 2008, 27, 254-258; c) B. Dutta, E. Solari, R. Scopelliti, K. Severin, Organometallics 2008, 27, 423-429; d) Y. Borguet, A. Richel, S. Delfosse, A. Leclerc, L. Delaude, A. Demonceau, Tetrahedron Lett. 2007, 48, 6334-6338; e) Y. Motoyama, S. Hanada, K. Shimamoto, H. Nagashima, Tetrahedron 2006, 62, 27792788; f) L. Quebatte, E. Solari, R. Scopelliti, K. Severin, Organometallics 2005, 24, 1404-1406; g) Y. Motoyama, S. Hanada, S. Niibayashi, K. Shimamoto, N. Takaoka, H. Nagashima, Tetrahedron 2005, 61, 10216-10226; h) L. Quebatte, M. Haas, E. Solari, R. Scopelliti, Q. T. Nguyen, K. Severin, Angew. Chem. 2005, 117, 1108; Angew. Chem. Int. Ed. 2005, 44, 1084-1088; i) L. Quebatte, R. Scopelliti, K. Severin, Eur. J. Inorg. Chem. 2005, 3353-3358; j) L. Quebatte, R. Scopelliti, K. Severin, Angew. Chem. 2004, 116, 1546; Angew. Chem. Int. Ed. 2004, 43, 1520-1524; k) B. T. Lee, T. O. Schrader, B. Martín-Matute, C. R. Kauffman, P. Zhang, M. L. Snapper, Tetrahedron 2004, 60, 7391-7396; 1) O. Tutusaus, S. Delfosse, A. Demonceau, A. F. Noels, C. Viñas, F. Teixidor, Tetrahedron Lett. 2003, 44, 8421-8425; m) O. Tutusaus, C. Viñas, R. Núñez, F. Teixidor, A. Demonceau, S. Delfosse, A. F. Noels, I. Mata, E. Molins, J. Am. Chem. Soc. 2003, 125, 11830-11831; n) B. de Clercq, F. Verpoort, Tetrahedron Lett. 2002, 43, 4687-4690; o) F. Simal, L. Wlodarczak, A. Demonceau, A. F. Noels, Eur. J. Org. Chem. 2001, 14, 2689-2695; p) F. Simal, L. Wlodarczak, A. Demonceau, A. F. Noels, Tetrahedron Lett. 2000, 41, 6071-6074.

[5] T. Pintauer, Eur. J. Inorg. Chem. 2010, 2449-2460.

[6] a) M. A. Fernández-Zúmel, K. Thommes, G. Kiefer, A. Sienkiewicz, K. Pierzchala, K. Severin, Chem. Eur. J. 2009, 15, 11601-11607; b) J. M. Muñoz-Molina, T. R. Belderraín, P. J. Pérez, Adv. Synth. Catal. 2008, 350, 2365-2372; c) J. Wolf, K. Thommes, O. Briel, R. Scopelliti, K. Severin, Organometallics 2008, 27, 4464 4474; d) K. Thommes, B. Içli, R. Scopelliti, K. Severin, Chem. Eur. J. 2007, 13, 6899-6907.

[7] a) M. N. C. Balili, T. Pintauer, Inorg. Chem. 2010, 49, 56425649; b) C. Ricardo, T. Pintauer, Chem. Commun. 2009, 30293031; c) M. N. C. Balili, T. Pintauer, Inorg. Chem. 2009, 48, 9018-9026; d) W. T. Eckenhoff, S. T. Garrity, T. Pintauer, Eur. J. Inorg. Chem. 2008, 563-571; e) W. T. Eckenhoff, T. Pintauer, Inorg. Chem. 2007, 46, 5844-5846; f) L. Quebatte, K. Thommes, K. Severin, J. Am. Chem. Soc. 2006, 128, 74407441.

[8] T. Pintauer, W. T. Eckenhoff, C. Ricardo, M. N. C. Balili, A. B. Biernesser, S. T. Noonan, M. T. Taylor, Chem. Eur. J. 2009, 15, $38-41$.

[9] a) R. Casolari, F. Felluga, V. Frenna, F. Ghelfi, U. M. Pagnoni, A. F. Parsons, D. Spinelli, Tetrahedron 2011, 67, 408-416; b) M. J. W. Taylor, W. T. Eckenhoff, T. Pintauer, Dalton Trans. 2010, 39, 11475-11482.

[10] K. Thommes, G. Kiefer, R. Scopelliti, K. Severin, Angew. Chem. 2009, 121, 8259; Angew. Chem. Int. Ed. 2009, 48, 81158119.

[11] Electrochemical redox potential for $\mathrm{Mn}^{+2} / \mathrm{Mn}^{0}$ is $-1.03 \mathrm{~V}$, see: Handbook of Chemistry and Physics, 62nd ed., CRC, Boca Raton, FL, 1982.

[12] J. M. Concellón, H. Rodríguez-Solla, V. del Amo, Chem. Eur. J. 2008, 14, 10184-10191.
[13] Commercial Mn is protected by an oxide layer, see: K. Takai, T. Ueda, T. Hayashi, T. Moriwake, Tetrahedron Lett. 1996, 37, 7049-7052.

[14] Activated $\mathrm{Mn}^{*}$, which is prepared by reduction of $\mathrm{Mn}^{\mathrm{II}}$ salts, can react with a variety of organyl halides (see ref. ${ }^{[12]}$ ).

[15] For selected examples, see: a) J. Y. Kang, B. T. Connell, J. Am. Chem. Soc. 2010, 132, 7826-7827; b) K. C. MacLeod, J. L. Conway, B. O. Patrick, K. M. Smith, J. Am. Chem. Soc. 2010, 132, 17325-17334; c) K. C. MacLeod, B. O. Patrick, K. M. Smith, Organometallics 2010, 29, 6639-6641; d) K. Namba, J. Wang, S. Cui, Y. Kishi, Org. Lett. 2005, 7, 5421-5424; e) M. Lombardo, S. Morganti, S. Licciulli, C. Trombini, Synlett 2003, 43-46; f) A. Fürstner, N. Shi, J. Am. Chem. Soc. 1996, 118, 12349-12357; g) A. Fürstner, N. Shi, J. Am. Chem. Soc. 1996, $118,2533-2534$.

[16] For selected examples, see: a) A. Gansäuer, M. Otte, L. Shi, J. Am. Chem. Soc. 2011, DOI: 10.1021/ja109362m; b) A. Gansäuer, L. Shi, M. Otte, J. Am. Chem. Soc. 2010, 132, 11858 11859 ; c) M. Paradas, A. G. Campaña, R. E. Estévez, L. A. de Cienfuegos, T. Jiménez, R. Robles, J. M. Cuerva, J. E. Oltra, J. Org. Lett. 2009, 74, 3616-3619; d) P. Wipf, J. P. Maciejewski, Org. Lett. 2008, 10, 4383-4386; e) A. Gansäuer, C.-A. Fan, F. Keller, J. Keil, J. Am. Chem. Soc. 2007, 129, 3484-3485; f) A. F. Barrero, M. M. Herrador, J. F. Quílez del Moral, P. Arteaga, M. Akssira, F. El Hanbali, J. F. Arteaga, H. R. Diéguez, E. M. Sánchez, J. Org. Chem. 2007, 72, 2251-2254; g) A. Gansäuer, H. Blum, M. Pierobon, J. Am. Chem. Soc. 1998, 120, 12849 12859.

[17] a) D. A. Everson, R. Shrestha, D. J. Weix, J. Am. Chem. Soc. 2010, 132, 920-921; b) M. R. Prinsell, D. A. Everson, D. J. Weix, Chem. Commun. 2010, 46, 5743-5745.

[18] K. Thommes, M. A. Fernández-Zúmel, C. Buron, A. Godinat, R. Scopelliti, K. Severin, Eur. J. Org. Chem. 2011, 249-255.

[19] H. T. Bonge, B. Pintea, T. Hansen, Org. Biomol. Chem. 2008, 6, 3670-3672.

[20] T. Nagano, J. Motoyoshiya, A. Kakehi, Y. Nishii, Org. Lett. 2008, 10, 5453-5456.

[21] X.-Q. Zhu, H.-Y. Wang, J.-S. Wang, Y.-C. Liu, J. Org. Chem. 2001, 66, 344-347.

[22] a) J.-B. Kim, I. Cho, Tetrahedron 1997, 53, 15157-15166; b) P. Boldt, L. Schulz, U. Klinsmann, H. Köster, W. Thielecke, Tetrahedron 1970, 26, 3591-3615.

[23] A. S. Biland, S. Altermann, T. Wirth, ARKIVOC 2003, 6, 164 169.

[24] S. Araki, Y. Butsugan, J. Chem. Soc., Chem. Commun. 1989, $1286-1287$.

[25] a) A. O. Chagarovskiy, O. A. Ivanova, E. R. Rakhmankulov, E. M. Budynina, I. V. Trushkov, M. Y. Melnikov, Adv. Synth. Catal. 2010, 352, 3179-3184; b) J.-P. Qu, C. Deng, J. Zhou, X.L. Sun, Y. Tang, J. Org. Chem. 2009, 74, 7684-7689; c) J. Fang, J. Ren, Z. Wang, Tetrahedron Lett. 2008, 49, 6659-6662; d) O. A. Ivanova, E. M. Budynina, Y. K. Grishin, I. V. Trushkov, P. V. Verteletskii, Eur. J. Org. Chem. 2008, 5329-5335; e) O. A. Ivanova, E. M. Budynina, Y. K. Grishin, I. V. Trushkov, P. V. Verteletskii, Angew. Chem. 2008, 120, 1123; Angew. Chem. Int. Ed. 2008, 47, 1107-1110; f) Y.-B. Kang, X.-L. Sung, Y. Tang, Angew. Chem. 2007, 119, 3992; Angew. Chem. Int. Ed. 2007, 46, 3918-3921.

[26] E. J. Corey, M. Chaykovsky, J. Am. Chem. Soc. 1965, 87, 13531364.

[27] F. González-Bobes, M. D. B. Fenster, S. Kiau, L. Kolla, S. Kolotuchin, M. Soumeillant, Adv. Synth. Catal. 2008, 350, 813816.

[28] S. R. Goudreau, D. Marcoux, A. B. Charette, J. Org. Chem. 2009, 74, 470-473.

[29] For examples of sequential or tandem reactions involving a Rucatalyzed radical addition, see: a) Y. Borguet, X. Sauvage, G. Zaragoza, A. Demonceau, L. Delaude, Beilstein J. Org. Chem. 2010, 6, 1167-1173; b) B. A. Seigal, C. Fajardo, M. L. Snapper, J. Am. Chem. Soc. 2005, 127, 16329-16332; c) B. Schmidt, M. 
Pohler, J. Organomet. Chem. 2005, 690, 5552-5555; d) C. W. Bielawski, J. Louie, R. H. Grubbs, J. Am. Chem. Soc. 2000, 122, 12872-12873.

[30] T. Arliguie, C. Border, B. Chaudret, J. Devillers, R. Poilblanc, Organometallics 1989, 8, 1308-1314.

[31] G. H. Hakimelahi, G. Just, Tetrahedron Lett. 1979, 20, 36433644.

[32] T. Nagano, J. Motoyoshiya, A. Kakehi, Y. Nishii, Org. Lett. 2008, 10, 5453-5456.
[33] Y.-C. Liu, B. Li, Q.-X. Guo, Tetrahedron 1995, 51, 9671-9680.

[34] L. Töke, Z. Hell, G. T. Szabó, G. Tótk, M. Bihari, A. Rockenbauer, Tetrahedron 1993, 49, 5133-5146.

[35] P. Boldt, L. Schulz, U. Klinsmann, H. Köster, W. Thielecke, Tetrahedron 1970, 26, 3951-3615.

[36] C. G. Hamaker, J.-P. Djukic, D. A. Smith, L. K. Woo, Organometallics 2001, 20, 5189-5199.

Received: February 7, 2011

Published Online: March 8, 2011 